\title{
KOMUNIKACIJA U FIZIOTERAPEUTSKOJ PRAKSI
}

\author{
Stevan Jovanović1, Divna Kekušr1, Biljana Stojanović Jovanović1 \\ Akademija srukovnih studija Beograd \\ Odsek Visoka zdravstvena škola
}

\begin{abstract}
APSTRAKT
Komunikacija se smatra najvažnijim aspektom prakse zdravstvenih radnika a komunikacioni odnos zdravstveni radnik-pacijent podrazumeva dve grupacije ljudi koje imaju različite pozicije odnosno, uloge koje određuju njihov interakcijski odnos. Proces komunikacije između fizioterapeuta i pacijenta sve se više prepoznaje i kao terapeutska praksa. Kroz komunikacione interakcije, fizioterapeuti mogu da obrazuju, motivišu, osnaže il oslobode, izraze empatiju ili autoritet, pokažu interes ili grade poverenje.

U fizioterapiji, kao i u drugim zdravstvenim profesijama, orijentisanim prema pacijentu, biopsihosocijalni $i$ njemu blizak, pristup u komunikaciji fokusiran na pacijenta su uspostavljeni kao vodiči i okviri za način na koji praktičari i treba da komuniciraju sa svojim pacijentima. Ovi komunikacioni modeli se koriste kako bi se podelila informacija kao i odgovornost ali i smanjile razlike u moći između zdravstvenog radnika-fizioterapeuta i pacijenta. U skladu sa tim, ovaj komunikacioni model je posebno usmeren na razumevanje potreba pacijenata i njihovog rešavanja u cilju što bolje perspektive svakog pacijenta. Razvijanje aktivne saradnje između pacijenta i terapeuta stvara odnos definisan kao "terapeutska alijansa" karakterisan empatijom, poverenjem i poštovanjem.

Mnogi oblici tretmana koje sprovode fizioterapeuti ne mogu biti uspešni bez doprinosa pacijenta i njegove motivacije za saradnju kako tokom same komunikacione interakcije, tako i izvan nje. komunikacione veštine pozitivno utiču na pacijentovu psihologiju a time i fiziologiju jer su one neodvojive a odnos između fizioterapeuta i pacijenta tokom procesa rehabilitacije, budi osećaj „saputništva“ na putu tokom kog se pruža prilika da se pacijent oslobodi svojih fizičkih, socijalnih i okolinskih ograničenja.
\end{abstract}

KLJUČNE REČI: komunikacij, a fizioterapeutska praksa, pacijent.

\section{ABSTRACT}

Communication is considered to be the most important aspect of the practice of healthcare professionals, and the communication relationship between the health care provider and the patient involves two groups of people who have different positions or roles that determine their interaction and relationship. The communication process between physiotherapist and patient is increasingly recognized as a therapeutic practice.

Through communication interactions, physiotherapists can educate, motivate, empower, or release, express empathy or authority, show interest, or build confidence. In physiotherapy, as well as in other patient-oriented, biopsychosocial and related health care professions, a patient-centered communication approach has been established as guides and frameworks for practitioners to communicate with their patients. These communication models are used to share information as well as accountability but also to reduce power disparities between the physiotherapist and the patient. Accordingly, this communication model is specifically aimed at understanding the needs of patients and addressing them in order to maximize the perspective of each patient. Developing active patient-therapist collaboration creates a relationship defined as a "therapeutic alliance" characterized by empathy, trust, and respect.

Many forms of treatment performed by physiotherapists cannot be successful without the patient's contribution and motivation to cooperate, both during and outside the communication interaction. communication skills have a positive effect on the patient's psychology and therefore physiology as they are inseparable, and the relationship between the physiotherapist and the patient during the rehabilitation process creates a sense of "companionship" on the path during which the patient is free from his or her physical, social and environmental limitations.

KEYWORDS: communication, and physiotherapy practice, patien

\section{UVODNA RAZMATRANJA}

Komunikacija se smatra najvažnijim aspektom prakse zdravstvenih radnika (profesionalaca zdravstvenih struka). Pristup u razmatranju odnosa zdravstveni radnik-pacijent podrazumeva da su to dve grupacije ljudi koje imaju različite pozicije odnosno uloge koje određuju njihov interakcijski odnos [1]. Proces komunikacije između fizioterapeuta i pacijenta sve se više prepoznaje i kao terapeutska praksa. Prema zaključcima Svetske konfederacije fizioterapeuta, komunikacione sposobnosti spadaju u osnovne stručne kompetencije u fizioterapeutskoj profesiji [2]. Kroz komunikacione interakcije, fizioterapeuti mogu da obrazuju, motivišu, osnaže il oslobode, izraze empatiju ili autoritet, pokažu interes ili grade poverenje [3].
Takođe, tokom komunikacije sa pacijentom, fizioterapeut usmerava i vodi razgovor čime obezbeđuje vrstu i potrebnu količinu informacija o stanju i okolnostima u kojima se pacijent odnosno klijent nalazi a koje olakšavaju ili ometaju njegove mogućnosti kao i o aspektima koje smatra značajnim za njegovo zdravlje i dobrobit [4]. Prema istraživanju Stenmara i Nordholma, sprovedenom na uzorku od 187 švedskih fizioterapeuta, većina njih je smatrala da je odnos pacijent-terapeut kao i resursi samog pacijenta najvažniji faktori za uspeh tretmana, čak više nego sama primena fizioterapeutskih metoda, tehnika i agenasa u sklopu tretmana [5].

Od 90-tih godina u fizioterapeutsku teoriju i praksu se uvodi termin „praksa zasnovana na dokazima“ koji podrazumeva metod

\section{Korespondent:}

Jovanović Stevan

ul.Drinčićeva 11a/66

11 000Beograd

jovanovicsstevan@gmail.com

Telefon: 0641124329 
kliničkog donošenja odluka u praksi koja integriše najkvalitetnije dostupne naučno istraživačke dokaze u naučno-stručnoj literaturi. U skladu sa tim, opšte je prihvaćeno mišljenje da fizioterapeuti treba da usmere svoje aktivnosti na promociju zdravog telesnog funkcionisanja koje se najčešće odnosi na telesnu posturu, pokret i kretanje a takođe i da u okviru terapeutske procene i dijagnostike, objektivno i efektivno izmere pomenute funkcionalne telesne karakteristike. Zbog toga su stručnjaci ovog profila često u iskušenju da se fokusiraju isključivo na fizičke aspekte i njihove objektivne mere, jer se to dobro uklapa i u skladu je sa praksom zasnovanom na dokazima. Pri tome, zanemaruje se holistički pristup koji je potreban kako bi se zaista pomoglo ljudima sa zdravstvenim problemima i određenim stepenima onesposobljenosti [6].

Postoji potreba za širim, integrativnim pristupom, gde fizioterapeutska praksa zavisi od šireg raspona veština i znanja nego što se to tradicionalno tvrdi [7]. Emocionalni i socijalni aspekti života pacijenata odnosno klijenata treba da budu integrisani u fizioterapeutski pristup. Činjenica je da raste istraživačko interesovanje za efekte određenih komunikativnih tehnika, kao što su motivacioni razgovor i savetovanje rezultati fizioterapijskog lečenja [8]. Studije su takođe pokazale da pacijenti to opažaju i da je komunikativna sposobnost terapeuta središnja karakteristika dobre fizioterapije [9].

\section{METOD}

Dostupna literatura pregledana je pretraživanjem elektronskih baza podataka (EBSCO Medline, EBSCO host, Science Direkt, ProQuest) koje su dostupne preko Konzorcijuma biblioteka Srbije za objedinjenu nabavku (KoBSon).

\section{KLJUČNE KARAKTERISTIKE BIOPSIHOSOCIJALNOG I TEORIJSKOG PRISTUPA U KOMUNIKACIJI USMERENOG NA PACIJENTA}

U fizioterapiji, kao i u drugim zdravstvenim profesijama, orijentisanim prema pacijentu, biopsihosocijalni pristupi su uspostavljeni kao vodiči i okviri za način na koji praktičari treba da komuniciraju sa svojim pacijentima [10]. Biopsihosocijalni pristup zdravstvenoj zaštiti zasniva se na ideji da su loše zdravstveno stanje ili fizička disfunkcija zasnovani ne samo na fizičkom problemu, već da postoji uticaj i drugih faktora kao što su nečija lična osećanja, događaji i okolnosti u nečijem životu kao i svest o zdravlju [11]. U kontekstu "zdravstvene komunikacije", biopsihosocijalni pristup zahteva od praktičara da pri proceni i uspostavljaanju funkcionalne terapeutske dijafnoze kao i planiranju i sprovođenju tretmana, ima u vidu biološke, socijalne i psihološke faktore, koji moraju biti ugrađene u efektivni komunikacioni pristup u kliničkoj praksi [12].

Prema autorima, ove tri komponente su međusobno povezane pa se opisuju kao "biopsihosocijalna komunikacija"[13]. Nadalje, ovakav pristup se opisuje kao "društveni razgovor" sa nekoliko pitanja koja terapeut postavlja u cilju postizanja balansa između psihosocijalnog i biomedicinskog sadržaja takvog razgovora [13]. U tom cilju, predlaže se upotreba "otvorenih pitanja" odnosno pitanja bez ponuđenih ili sugerisanih odgovora [14].

\section{PRISTUP KOMUNIKACIJI FOKUSIRAN NA PACIJENTA}

Pristup u komunikaciji fokusiran na pacijenta je blizak biopsihosocijalnom pristupu. Glavna karakteristika ovog pristupa je ko- munikacioni model koji se koristi kako bi se podelila informacija kao i odgovornost ali i smanjile razlike u moći između zdravstvenog radnika-fizioterapeuta i pacijenta, koju pacijenti mogu osećati zbog situacije u kojoj su se našlii. U skladu sa tim, ovaj komunikacioni model je posebno usmeren na razumevanje potreba pacijenata i njihovog rešavanja u cilju što bolje perspektive svakog pacijenta [15]. Komunikacija sa fokusom na pacijenta, podrazumeva iskazivanje poštovanja i uvažavanje znanja i iskustva svakog pojedinog pacijenta [15]. Komunikaciona strategija koja se ovde upotrebljava teži da uključi i stimuliše pacijentov narativ i dobije informacije o iskustvima pacijenta [16]. Odluke o tretmanu terapeut deli sa svojim pacijentom a odnost terapeut-pacijent se opisuje kao „kolaborativna alijansa“[17]. Specifične karakteristike komunikacionog modela usmerenog na pacijenta su upotreba pitanja „sa otvorenim krajem“ i pitanja koja ne usmeravaju odgovor („pitanja bez direktive“). Zbog toga, komunikacija uključuje emocionalni aspekt ličnih iskustava a izbegava se prekidanje pacijentovog narativa [17].

U studiji Jensena i saradnika [18]. navodi se da pristup fokusiran na pacijenta uključuje veštine „dobrog slušanja“ pacijenta što omogućuje veće razumevanje socijalnog i psihološkog konteksta u kome se pacijent nalazi. Ishod lečenja odnosno rehabilitacije pacijenta svakako može biti unapređen ako se upoznaju i uzmu u obzir pomenuti konteksti i emocionalno-psihološki stavovi odnosno preferencije [19]. Pristup u kome je pacijent na centralnom mestu, omogučava da se tokom procesa fizioterapeutskog tretmana razvije međusobno razumevanje problema, prioriteta i postavljanje ciljeva [20].

\section{TERAPEUTSKA ALIJANSA (TERAPIJSKI SAVEZ)}

Odnos između kljenta odnosno pacijenta i terapeuta se u literaturi najčešće označava kao "terapeutska alijansa" i potekao je iz prakse u oblasti kliničke psihologije. Po definiciji, to je svesna i aktivna saradnja između pacijenta i terapeuta [21]. Pregledom literature, mogu se prepoznati još neki termini koji definišu ovaj odnos na gotovo identičan način a to su "terapijski odnos" $i$ "raport pacijenta” Već i sama reč engleskog jezika "rapport” označava: “ odnos karakterisan usaglašenošću, uzajamnim razumevanjem i empatijom što čini komunikaciju mogućom i lakom” [22].

Termin “terapijski odnos” je definisan empatijom, poverenjem i poštovanjem, iskazanim kroz saradnju i komunikaciju [23]. Pomenuti termini označavaju gotovo identičan narativ koji podrazumeva saradnju i reciprocitet u komunikaciji između terapeuta i klijenta u najširem smislu. U literaturi pretežno vezanoj za kliničku psihologiju i psihoterapiju, razmatra se pojam terapijske alijanse i u tom smislu predlaže teorijski razvoj koncepta saveza-alijanse, sugerišući da postoje varijacije u različitim fazama terapije i da se one mogu objasniti zahvaljujući dinamičkoj prirodi saveza. Naime, razlikuju se dve faze terapijske alijanse: prva, pronađena u ranim fazama terapije, zasnivala se na pacijentovoj percepciji terapeuta kao onoga koji daje podršku i potporu, dok je druga, tipičnija za kasniji period terapije i predstavljena je kao kolaborativni odnos između pacijenta i terapeuta sa svrhom prevazilaženja pacijentovog problema i podrazumeva podelu odgovornosti u radu na postizanju ciljeva terapije i osećaju zajedništva [24].

Istraživanja ukazuju da se efekti fizioterapeutskog tretmana mogu značajno unaprediti tzv. opštim medijatorima kao što su efektivna komunikacija i psihološka interakcija između pacijenta i kliničara [25]. Upravo terapeutska alijansa je odnos koji podrazumeva ove aspekte. Ona je centralna komponenta terapeutskog 
procesa i određuje ishod tretmana [26]. Terapeutska alijansa se zasniva na Frojdovoj teoriji transfera i povratnog transfera[24]. To je model koji se sastoji od elemenata kao što su dogovor i usaglašenost o ciljevima tretmana, dogovor i usaglašenost o zadacima tretmana i razvoj lične veze koja podrazumeva recipročna pozitivna osećanja između klijenta i terapeuta [25].

\section{UČEŠĆE PACIJENTA U KOMUNIKACIJI}

Učešće pacijenta u komunikaciji je esencijalna komponenta fizioterapeutskog tretmana. Sam cilj fizioterapeutskog tretmana je da optimizuje pacijentovu funkciju pokreta i kretanja[2]. Zbog toga, aktivna terapija, vežbe i strategije upravljanje pacijenata sopstvenim rehabilitaciono terapijskim procesom koje oni treba da sprovode u njihovim dnevnim aktivnostima, ima centralno mesto u fizioterapeutskom tretmanu [27]. Takav koncept zahteva aktivno učešće pacijenta kao i preuzimanje izvesne odgovornosti za tok procesa njihove rehabilitacije. Mnogi oblici tretmana koje sprovode fizioterapeuti ne mogu biti uspešni bez doprinosa pacijenta i njegove motivacije za saradnju kako tokom same komunikacione interakcije, tako i izvan nje.

Pacijent kao individua, mora biti uključen i aktivno učestvovati u svakoj fazi tretmana i nikako ne može biti pasivni primalac terapije. On mora pokazati posvećenost i aktivno učešće u procesu sopstvene rehabilitacije. Fizioterapeuti kroz komunikaciju sa pacijentom sprovode savetodavni rad i edukaciju i time mu daju podršku u ovladavanju odgovarajućim aktivnostima. Jedan od osnovnih profesionalnih ciljeva fizioterapeuta je efikasnost odnosno samoefikasnost. Ovaj cilj se ne može postići bez efektivne komunikacije i saradnje sa pacijentom. U kontekstu fizioterapije efektivna komunikacija i saradnja sa pacijentom podrazumeva podsticanje i razvijanje njegovih kapaciteta da kroz tu saradnju, samostalno sprovede naučene vežbe i ostale propisane režime koji su dizajnirani da optimizuju njegovo fizičko funkcionisanje [28].

Efikasnost mnogih aspekata fizioterapije, zasniva se na učešću $\mathrm{i}$ angažovanju pacijenata koje nastaje kao posledica reciprociteta $\mathrm{u}$ odnosu sa fizioterapeutom[28]. Smatra se da učešće pacijenta kao i pridržavanje propisanom režimu funkcionisanja, neposredno za vreme trajanja tretmana kao i izvan tih perioda, zavisi od kvaliteta komunikacionog odnosa pacijent-fizioterapeut [8].

\section{ZAKLJUČAK}

U svojoj praksi, fizioterapeuti danas ne koriste često biopsihosocijalni i pristup fokusiran na pacijenta, baveći se uglavnom biomedicinskim aspektima problema koje ističu njihovi pacijenti u komunikaciji. Fizioterapeuti obraćaju malo pažnje na psihosocijalne aspekte stanja u kojima se nalaze pacijenti. Takođe, prilikom komunikacija sa pacijentom-klijentom, postavljaju „zatvorena pitanja“(na koja se uglavnom odgovara sa da ili ne), iniciraju konverzaciju, prekidaju pacijente i donose odluke bez dovoljnog

\section{POVRATNA SPREGA U VERBALNOJ I NEVERBALNOJ KOMUNIKACIJI}

Tokom procesa tretmana, uobičajeni pristup fizioterapeuta je da komunikacijom navodi pacijenta na izvođenje određenih aktivnosti pomoću kombinacije verbalnog uputstva i objašnjavanja, vizuelne demonstracije i manuelng vođenja i asistencije. Ovakav vid komunikacije sadrži elemente fidbeka, odnosno povratne informacije, koju fizioterapeut pruža pacijentu kao odgovor na njegove aktivnosti. U literaturi se komunikaciona povrtana sprega između fizioterapeuta i pacijenta naziva augmentativni ili spoljašnji fidbek. Augmentativni fidbek je informacija dobijena iz spoljnog izvora kao dopunskog, u odnosu na percepciju onoga ko izvodi pokret. On može biti verbalne ili neverbalne prirode i može se pružiti istovremeno sa izvođenjem određene motorne aktivnosti, odmah nakon nje, ili znatno kasnije[29].

Istraživanja govore da fizioterapeuti u komunikaciji koriste najviše verbalno i fizičko vođenje (vođenje fizičkim kontaktom). Verbalne sugestije su uglavnom u obliku kratkih komentara [29]. Glavni značaj vođenja fizičkim kontaktom odnosno primene spoljašnjeg manuelnog fidbeka je korišćenje taktilnih informacija kako bi se poboljšala orijentacija pokreta koje izvode pacijenti u prostoru i time dobio odgovarajući i korektno izveden pokret u toku terapijskog procesa.

Vizuelno vođenje odnosno vizuelni fidbek se koristi u manjoj meri. Povratne informacije mogu da poboljšaju motoričko učenje kod zdravih subjekata. Tokom tretmana, pacijent koristi povratne informacije za detekciju grešaka u izvođenju motornih aktivnosti kako bi tokom terapijskog tretmana bio vođen ka očekivanom cilju. Pažljivo planiranje sadržaja i pažnja usredsređena na povratne informacije mogu znatno povećati efikasnost terapijskog procesa. Komunikacija pacijenata i fizioterapeuta sa sadržajem fidbeka, poseduje i društveno afektivne elemente koji utiču na atmosferu koja upravlja ovom interakcijom.

Prema istraživanju Amoudi i saradnika, pozitivne komunikacione veštine fizioterapeuta, igraju značajnu ulogu u redukovanju osećaja bola kod ortopedskih pacijenata kao i smanjenju depresivnih elemenata a povećavaju motivaciju. Kako autori navode, komunikacione veštine pozitivno utiču na pacijentovu psihologiju a time i fiziologiju jer su one neodvojive [30]. U literaturi se navodi da odnos između fizioterapeuta i pacijenta tokom procesa rehabilitacije, budi osećaj „saputništva“ na putu tokom kog se pruža prilika da se pacijent oslobodi svojih fizičkih, socijalnih i okolinskih ograničenja[7].

uvažavanja iskustava stavova ili potreba njihovih pacijenata.

Svakako da postoji potreba sticanja znanja i veština u oblasi komunikacija još tokom studija fizioterapije, gde će studenti naučiti kako da integrišu efektivne komunikacijske veštine u svoju buduću praksu. Takođe razvijanje veština komunikacije u terapeutskoj praksi značajno unapređuje efekte terapijskog tretmana, čime one postaju njegov izrazito važan element. 


\section{LITERATURA}

1. Kekuš D. Komunikacije u profesionalnoj praksi zdravstvenih radnika, Visoka zdravstvena škola strukovnih studija; Digital Art, 2010.

2. World Confederation for Physical Therapy (WCPT). Policy statement: description of physical therapy. Preuzezeto 18.01 2020. Dostupno na: http://www.wcpt.org/policy/ps.

3. Hiller A. Toward relationship-centred care: patient-physiotherapist interaction in private practice. (Doctoral dissertation, The University of Melbourne). Retrieved from Preuzeto 2017.

Dostupno na: https://minerva-access.unimelb.edu.au/ handle/11343/129510.

4. Afrell M, Rudebeck CE. 'We got the whole story all at once': physiotherapists' use of key questions when meeting patients with long-standing pain. Scand J Caring Sci. 2010 Jun;24(2):281-9. doi: 10.1111/j.1471-6712.2009.00718.x. Epub 2009 Dec 20.

5. Stenmar L, Nordholm L. Swedish physical therapists' beliefs on what makes therapy work. Phys Ther. 1994;74:1034-1039.

6. Jones M, Grimmer K, Edwards I, Higgs J and Trede F. Challenges in applying best evidence to physiotherapy practice, health and clinical reasoning mode to facilitate evidence-based practice. Internet Journal of Allied Health Sciences and Practice 2006: 4: 1-9.

7. Heckman KA, Cott CA. Home-based physiotherapy for the elderly, a different world. Physiotherapy Canada 2005: 57: 274-83.

8. Lonsdale C, Hall A.M., Williams G.C, McDonough S.M., Ntoumanis N, Murray A. Hurley D.A. Communication style and exercise compliance in physiotherapy (CONNECT). A cluster randomized controlled trial to test a theory-based intervention to increase chronic low back pain patients' adherence to physiotherapists' recommendations: study rationale, design, and methods. BMC Musculoskelet Disord 13, 104. Preuzezeto: 2020. Dostupno na: https://doi.org/10.1186/1471-2474-13-104.

9. Cooper K. Smith B. H. Hancock. Patient-centredness in physiotherapy from the perspective of the chronic low back pain patient. Physiotherapy 2008:94(3)244-52. doi:10.1016/j. physio.2007.10.006

10. Pinto R. Z, Ferreira M. , Oliveira V. C., Franco M. R, Adams R., Maher C. G. Ferreira P. H. Patient-centred communication is associated with positive therapeutic alliance: a systematic review. Journal of Physiotherapy 2012:58(2) 77-87.

11. Engel G. L. The need for a new medical model: a challenge for biomedicine. Science, 1977: 196 (4286)129-36.

12. Epstein R. M, Morse D. S, Williams G. C, leRoux P, Suchman A. L. Quill, T. E. Clinical practice and the biopsychosocial approach. In R. M. Frankel, T. E. Quill \& S. H. McDaniel (eds.), The biopsychosocial approach: past, present, Rochester, New York: The University of Rochester Press; 2013.

13. Roter D. L, Stewart M,Putnam S. M, Lipkin M. Stiles W, Inui T. S. Communication patterns of primary care physicians. Journal of the American Medical Association 1997. 277(4) 350-56. doi:10.1001/jama.277.4.350.

14. Smith R. C, Fortin A. H, Dwamena F. Frankel R. M. An evidence-based patient-centered method makes the biopsychosocial model scientific. Patient Education and Counseling, 2013: 91(3) 265-70. doi:10.1016/j.pec.2012.12.010).

15. Bensing J. Bridging the gap. The separate worlds of evidencebased medicine and patient-centered medicine. Patient Education and Counseling 2000:39(1)17-25. doi:10.1016/s0738-3991(99)00087-7

16. Epstein R. M, Street Jr. R. .The values and value of patientcentered care. Annals of Family Medicine 2011 : 9 (2), 100-03. doi:10.1370/ afm.1239

17. Hiller A, Delany C. Communication in physiotherapy: challenging established theoretical approaches. In B.E. Gibson, D.A. Nicholls, J. Setchell, \& Synne Groven, K (eds.), Manipulating practices: A critical physiotherapy reader Norway: Cappelen Damm Akademisk. Available: Preuzezeto 2018.

Dostupno na: https://press.nordicopenaccess.no/index.php/noasp/catalog/book/29.)

18. Jensen G, Gwyer J, Shepard K and Hack L Expert practice in physical therapy. Physical Therapy 2000: 80: $28-43$.

19. Jones R Evidence-based practice and health policy development, the link between knowledge and action. Physiotherapy2004; 91:14-21

20. Brown JB, Weston, WW and Stewart MA Patient centred interviewing: Finding common ground. Canadian Family Physician 1989; 35:153-57.

21. Ackerman SJ, Hilsenroth MJ. A review of therapist characteristics and techniques positively impacting the therapeutic alliance. Clin Psychol Rev 2003;23(1):1-33.

22. Merriam, Webster dictionary Preuzezeto: 2020. Dostupno na: https://www.merriam-webster.com/dictionary/rapport)

23. Cole MB, McL ean V. Therapeutic relationships re-defined. Occup Ther Ment Health 2003;19(2):33-56.

24. Ardito RB, Rabellino D. Therapeutic alliance and outcome of psychotherapy: historical excursus, measurements, and prospects for research. Front Psychol. 2011; 2:270. Published 2011 Oct 18. doi:10.3389/fpsyg.2011.00270

25. Babatunde F, MacDermid J. MacIntyre N. Characteristics of therapeutic alliance in musculoskeletal physiotherapy and occupational therapy practice: a scoping review of the literature. BMC Health Serv Res Preuzezeto 2020.

Dostupno na: https://doi.org/10.1186/s12913-017-2311-3

26. Graves TA, Tabri N, Thompson-Brenner H, Franko DL, Eddy KT, Bourion-Bedes S, Bron A, et al. A meta-analysis of the relation between therapeutic alliance and treatment outcome in eating disorders. Int J Eat Disord. 2017; 50:323-40.

27. Higgs J, RefshaugeK, Ellis, E. Portrait of the physiotherapy profession. Journal of Interprofessional Care. 2001; 15(1) 79-89. doi:10.1080/13561820020022891

28. Redmond R, Parrish M. Variables influencing physiotherapy adherence among young adults with cerebral palsy. Qualitative Health Research 2008;18(11)1501-510. doi:10.1177/1049732308325538.

29. Hartveld A. RHegarty J. Augmented Feedback and Physiotherapy Practice. Physiotherapy 1996; 82 (8):480-90.

30. Amoudi M., Anabtawi R., Bzoor A., Keelani S., Abu Hassan W. The Effectiveness of Positive Communication Skills in Reducing Pain during Physiotherapy Session: A Quantitative Result from Questionnaire Surveys of Palestinian Orthopaedic Patients. Universal Journal of Public Health 20175(1): 17-24, doi: 10.13189/ujph.2017.050103. 